\title{
Persistence and Adherence with Urinary Antispasmodic Medications Among Employees and the Impact of Adherence on Costs and Absenteeism
}

\author{
Nathan L. Kleinman, PhD; Kevin Odell, PharmD; Chieh-I Chen, MPH; \\ Amy Atkinson, MS; and Kelly H. Zou, PhD, PStat
}

\begin{abstract}
BACKGROUND: Overactive bladder (OAB) and related conditions, such as urge urinary incontinence (UI), can interfere with work, leisure activities, and healthy sleep patterns.
\end{abstract}

OBJECTIVES: To report (a) employee urinary antispasmodic (UA) medication persistence and adherence; (b) the impact of salary and copay on adherence; and (c) the impact of UA adherence on medical, pharmacy, sick leave (SL), short- and long-term disability (STD, LTD), workers' compensation costs, work absence days, and turnover.

METHODS: This retrospective study used a 2001-2011 database of claims, payroll, and demographic data from 27 large U.S. employers. Employees aged 18-64 years taking UA medications with health plan enrollment from 6 months before the index UA medication prescription to 12 months after were included. Persistence (days until first $\geq 30$-day gap in UA medication supply) and adherence (percentage of the annual post-index period with available medication) were assessed using survival analysis and generalized linear regression models that controlled for demographics, job-related factors, copay, and pre-index employee benefit utilization.

RESULTS: 2,960 employees met study criteria. Median days of persistence by $O A B$ subtype were $76,82,43,66$, and 60 for urge $U I$, mixed $U I$, nocturnal $\mathrm{UI}$, other $\mathrm{OAB}$, and no diagnosis, respectively $(P<0.05$ for urge and mixed vs. no diagnosis). Increased copay and copay as a percentage of salary were associated with lower adherence. Employees with $\geq 80 \%$ adherence had lower medical, SL, and STD and higher overall drug costs than employees with $<80 \%$ adherence.

CONCLUSIONS: This study suggests potential economic benefits to employers from increased UA adherence. Additionally, economic factors such as ability to pay influence adherence to UA medications.

J Manag Care Pharm. 2014;20(10):1047-56

Copyright @2014, Academy of Managed Care Pharmacy. All rights reserved.

\section{What is already known about this subject}

Overactive bladder (OAB) affects between $16.5 \%$ and $28.7 \%$ of the U.S. adult population, with higher prevalence for women (17\%-30\%) than for men (16\%-17\%). For both genders, prevalence increases with age.

Medications prescribed to address OAB aim to reduce the number of incontinence episodes by relaxing the smooth muscle in the bladder and decreasing bladder contractions.
UA medical compliance is relatively poor due to high rates of adverse effects such as dry mouth, constipation, blurred vision, erythema, pruritus, fatigue, sweating, and urinary retention. One-year persistence of UA medications is only 5\%-35\%.

\section{What this study adds}

We conducted a retrospective analysis of employer claims, salary, and demographic data from the Human Capital Management Services Research Reference Database. Urinary antispasmodic (UA) persistence and adherence (proportion of days covered) were assessed using survival analysis and generalized linear regression models that controlled for demographics, salary, copay, and pre-index employee benefit utilization.

Economic factors such as ability to pay influence adherence to UA medications. Increased copay and copay as a percentage of salary each were significantly associated with lower adherence.

This study also quantified the impact of employee UA adherence on medical and prescription drug costs, work days missed, and costs due to work absence (sick leave, short- and long-term disability, and workers' compensation) and employee turnover. Employees with at least $80 \%$ adherence had significantly lower medical, sick leave, and short-term disability costs and higher overall drug costs than those with lower adherence.

( veractive bladder $(\mathrm{OAB})$ is characterized primarily by urinary urgency, which may include urinary incontinence, and may be associated with increased urinary frequency and nocturia. ${ }^{1}$ Studies based on survey responses have shown the prevalence of $\mathrm{OAB}$ among U.S. adults to be between $16.5 \%$ and $28.7 \% .^{2-4}$ In general, prevalence values for women (17\%-30\%) are higher than those for men (16\%-17\%), ${ }^{2,3}$ and prevalence increases in age among both genders., $2,4,5$ Published prevalence results for employed populations are limited, but in an Internet survey among 40- to 65-year-old employees, Sexton et al. (2009) found survey-based OAB prevalence to be $37.6 \%$ for women and $18.6 \%$ for men. ${ }^{6}$

In addition to its high prevalence, the impact of OAB symptoms on patients is also concerning. OAB has been shown to be associated with impairments in a wide range of quality of life 
aspects, including work and leisure activities, mental health, sexual function, and sleep. ${ }^{7-13}$

Urinary antispasmodic (UA) medications used to treat $\mathrm{OAB}$ commonly include fesoterodine, tolterodine, oxybutynin, solifenacin, darifenacin, trospium, and flavoxate. ${ }^{14-25}$ These medications are competitive antagonists of acetylcholine at muscarinic cholinergic receptors that relax the smooth muscle in the bladder and decrease bladder contractions. Imipramine ${ }^{26}$ and hyoscyamine ${ }^{27}$ also have anticholinergic properties and have been used to treat OAB symptoms.

UA medications moderately reduce the number of incontinence episodes, urinations, and urgency episodes and improve health-related quality of life. ${ }^{28}$ However, compared with placebo, UA medications are associated with higher rates of adverse effects, including dry mouth, constipation, blurred vision, erythema, pruritus, fatigue, sweating, and urinary retention. ${ }^{28}$

These adverse effects have contributed to generally poor UA medication compliance. ${ }^{29}$ Discontinuation rates within the first 30 days of medication use have been high (43\%-83\%), ${ }^{30-33}$ with only 5\%-35\% persisting for 1 year. ${ }^{31,33-36}$ Several studies have examined adherence, as measured by proportion of days covered (PDC) or the similar metric, medication possession ratio. Only 5\%-30\% of UA medication users were at least $80 \%$ adherent over each study's time frame (6-12 months postindex). ${ }^{31,32,37}$

Although medication cost and related factors involving insurance coverage have been identified as reasons for discontinuing UA medications, ${ }^{38,39}$ we are not aware of any claims studies that measured the impact of copay or salary (or income) on likelihood of discontinuance, persistence, or adherence. In 1 study, Sears et al. (2010) suggested that the higher compliance values found in their study of patients with $\$ 0$ copay level (compared with other studies where patients paid copays) were an indication that cost may impact compliance. ${ }^{40}$ In another study, Harpe et al. (2007) found that prescription insurance coverage was much more important in the decision to use drug therapy to control OAB symptoms than any of the health-related quality of life components studied. ${ }^{41}$

Few studies have examined the impact of UA adherence on health care costs. In a population of older adults with OAB, Balkrishnan et al. (2006) found that increased UA medication possession ratio was associated with lower annual health care costs, ${ }^{42}$ and a study by Ko et al. (2006) used results from the literature to demonstrate that health care costs for OAB-induced comorbidities were higher for UA medications that had higher discontinuation rates. ${ }^{43}$ Prior research has been published showing higher rates of adherence being associated with lower health care costs in some hypertension, diabetes, hypercholesterolemia, asthma, depression, and cardiovascular disease populations. ${ }^{44-51}$ No studies were found that examined the impact of UA adherence on absences from work or turnover rates.
In addition to quantifying UA medication persistence and adherence in an employed population, the objectives of this study that add to the prior literature included determining the impact of salary and copay on adherence and measuring the impact of UA adherence on medical, pharmacy, sick leave (SL), short- and long-term disability (STD, LTD), workers' compensation costs, work absence days, and turnover. Our hypotheses were that high copay, or high copay as percentage of salary, was associated with lower medication adherence and that higher adherence was associated with lower medical, sick leave, STD and LTD, workers' compensation costs, work absence days, and turnover.

\section{Methods}

\section{Database}

This study used a retrospective 2001-2011 Human Capital Management Services (HCMS) Research Reference Database (RRDb) of claims, payroll, and demographic data from nearly 1,500,000 employees dispersed across the United States. The $\mathrm{RRDb}$ represents various industries, including communications, transportation, finance, health care, and retail, and contains employee-specific information on demographics, salary and payroll, company type, job type, employment status, health plan, and work absence. HCMS collects these data from third-party administrators, disability insurers, and employer human resource and payroll systems in order to provide data warehousing, analysis, and consultation services to the employers. The employers are self-insured and encompass a wide variety of health plans. The employees represented in the $\mathrm{RRDb}$ are found in every state in the United States. The RRDb has been used in many prior published studies. ${ }^{45,52-54}$

\section{Study Population}

To measure persistence, adherence, and the impact of copay and salary on adherence, employees prescribed a UA medication during 2001-2011 were studied. UA medications included fesoterodine, tolterodine, oxybutynin, solifenacin, darifenacin, trospium, flavoxate, imipramine, and hyoscyamine. No specific diagnosis was required, unless the patient's index UA medication was flavoxate, imipramine, or hyoscyamine. Since these 3 medications are also used for conditions outside the scope of this study, they required a urinary incontinence (UI) or $\mathrm{OAB}$ diagnosis (primary, secondary, or tertiary International Classification of Diseases, Ninth Revision, Clinical Modification [ICD-9-CM] codes 596.51, 596.59, 788.30, 788.31, 788.33, $788.36,788.41$, or 788.43 ) within 6 months prior to the initial drug prescription or within 30 days after the initial drug prescription for the prescription to count as a UA medication.

To determine the impact of adherence on employee-related outcomes, 2 cohorts from the overall group were defined: adherent employees (those with $\geq 80 \%$ adherence) and nonadherent controls (employees with $<80 \%$ adherence). The index 
date for each employee was the date of the first UA prescription fill in the drug claims database.

\section{Inclusion and Exclusion Criteria}

All employees were required to have 6 months of employment and health plan enrollment before and 12 months after the index date. Employees were aged 18 to 64 years throughout the 18 -month study period. Employees not meeting these requirements were excluded.

\section{Descriptive Characteristics and Outcomes}

The descriptive characteristics that were examined among the employees prescribed UA medications included age, gender, marital status, race, annual salary, tenure (years with employer), exempt status (exempt employees are not eligible for overtime pay), full-time/part-time status, industry, union/ nonunion status, health plan carrier, OAB-related diagnoses, region (based on the first digit of the employee's ZIP code), average post-index UA medication copay (per 30-day supply), post-index copay as a percentage of salary (the employee's average copay for a 30-day supply of UA medication divided by the employee's monthly salary), Charlson Comorbidity Index ${ }^{55}$ (CCI), and pre-index cost and absence day values. CCI and preindex cost and absence day values were calculated during the 6 months prior to the index date.

UA medication persistence was measured as the time from the index UA prescription to the beginning of a 30-day or more gap in medication supply (during the year after the index date). Persistence was calculated for each $\mathrm{OAB}$ subtype, including urge UI (ICD-9-CM 788.31), mixed UI (ICD-9-CM 788.33), nocturnal UI (ICD-9-CM 788.36), other OAB (ICD-9-CM $596.51,596.59,788.30,788.41$, or 788.43 ), and those with no UI/OAB diagnosis. In this study, UA medication adherence (specifically PDC) was defined as the percentage of days during the year after the index prescription date wherein the employee had a supply of UA medication available. Persistence and adherence were calculated from prescription claims information.

The annual employee-related cost and absence day outcomes in the study were calculated over each employee's 12-month post-index enrollment period and compared between the adherent and nonadherent cohorts. Cost values were adjusted for inflation to June 2011 U.S. dollar values using medical services, prescription drug, and all consumer goods Consumer Price Indices. ${ }^{56}$

Direct cost outcomes included medical and drug costs (employer- and member-paid amounts for all medical and prescription pharmacy claims). Four types of indirect cost and absence outcomes were included: sick leave, STD and LTD, and workers' compensation. Sick leave costs and absence days comprised actual payments made to employees and number of days absent as detailed in payroll data. STD and LTD costs and absence days included actual payments made to employ- ees and number of days absent during leaves as detailed in disability insurance carrier data. Workers' compensation costs comprised actual medical and pharmacy payments for workrelated injury claims as well as payments made to employees as salary replacement while absent due to a work-related injury. Workers' compensation absence days were defined as the number of days absent during a workers' compensation leave and were obtained from workers' compensation claims data.

The employee turnover rate was measured as the percentage of employees in each cohort (with available termination information from human resource data) who left their employers during the 12- to 18-month period after the index date.

\section{Statistical Analysis}

For persistence measures, time-to-event survival analyses using Weibull distributions were used to model the expected time until a 30-day gap in medication supply. The survival models included and accounted for censored observations for employees with medication persistence longer than 1 year. A generalized linear model with a gamma distribution and a log link function was used to measure the impact of copay and salary on adherence. This model controlled for daily copay, copay squared, natural $\log (\ln )$ of annual salary, insurance carrier, UI/OAB diagnosis, age, gender, marital status, race, exempt, ZIP code region, industry, union status, CCI, $\ln$ (prior medical costs +1$)$, and $\ln$ (prior drug costs +1 ), where $\ln$ is the natural logarithm. A second generalized linear adherence model was also run that controlled for "daily copay as a percentage of daily salary" and for the square of "daily copay as a percentage of daily salary" in place of the copay, copay squared, and $\ln$ (annual salary) variables controlled for in the first adherence model.

When comparing post-index cost, absence days, and turnover outcomes between the employees with $\geq 80 \%$ adherence and those with $<80 \%$ adherence, each outcome was modeled separately as described above, and each absence analysis was run on the subset of employees who were eligible for the given absence benefit. For costs and absence days, two-part regression models were used to better account for the non-normal distributions of the data. The first part utilized logistic regression to model the likelihood of having any costs or absence days, and the second part used generalized linear models with a gamma distribution and a log link function to model the costs or absence days of those employees with nonzero costs or days. Logistic regression was used to model turnover rates. The regression models controlled for differences between cohorts in age, gender, marital status, race, exempt status, insurance carrier, union status, full-time status, $\ln$ (annual salary), ZIP code region, industry, pre-index $\mathrm{CCI}, \ln$ (prior medical costs +1 ), $\ln$ (prior drug costs +1 ), and $\ln$ (prior lost time cost or days values +1$)$. Variables were eliminated from the regression models only when necessary to obtain model convergence and fit. 
FIGURE 1 Selection of Study Cohorts

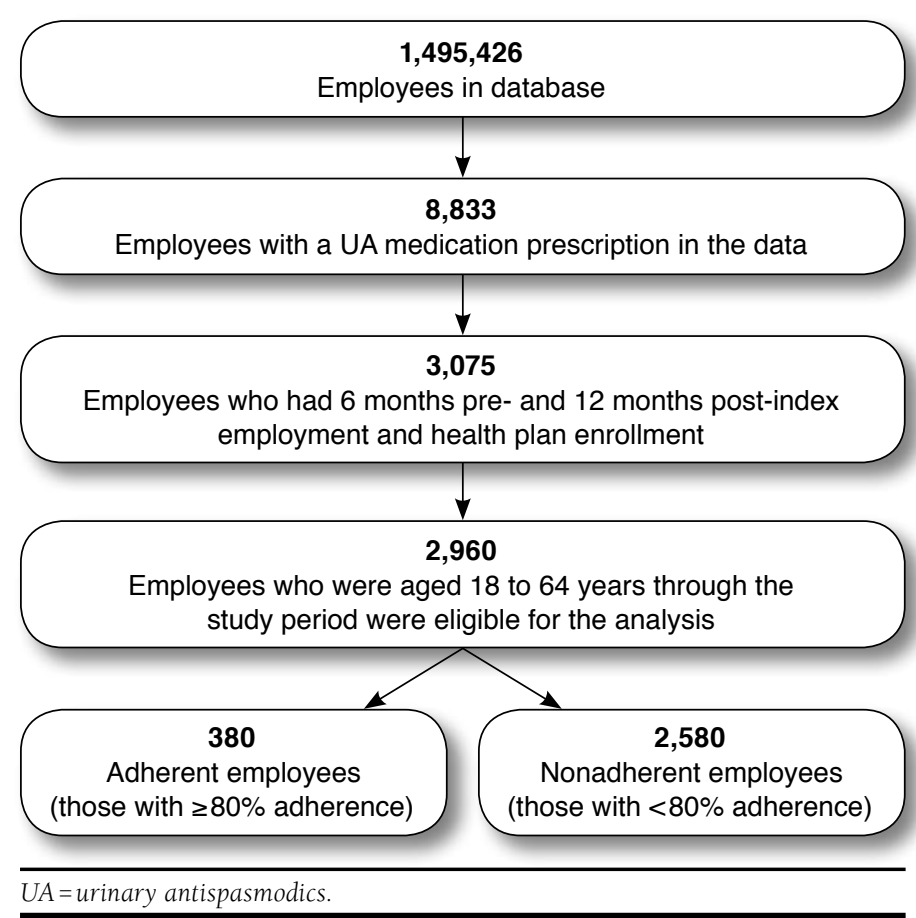

All $P$ values are two-sided, and statistical significance was reached when $P<0.05$. All statistical analyses were performed using SAS version 9.2 (SAS Institute Inc., Cary, NC).

\section{Results}

Of 1,495,426 total employees, 8,833 had a UA medication prescription in the data, and 3,075 had 6 months pre- and 12 months post-index employment and health plan enrollment (Figure 1). Of these, 2,960 were aged 18 to 64 years throughout the study period and were eligible for analysis, with 380 having $\geq 80 \%$ adherence and 2,580 having $<80 \%$ adherence.

Table 1 provides the descriptive characteristics of the overall study population. The average age of the employees was 46.65 years, and $70.3 \%$ were female. The average annual salary was $\$ 55,818$, and on average, these employees had been with their current employers for 10.84 years. Over half (55\%) had no UI/ $\mathrm{OAB}$ diagnosis in their medical claims data during the study period, and nearly $40 \%$ had an "Other OAB" ICD-9-CM code.

The UA persistence models found that the median time until a $\geq 30$-day gap in medication supply was 64 days, with $70 \%$ maintaining persistence beyond 1 month. Only $10 \%$ of employees were persistent for 9 months, and only 5\% were persistent for 1 year. Figure 2 shows the adjusted persistence curves and median persistence times for the 5 diagnosis subgroups. After controlling for other factors, employees with urge UI and mixed UI had statistically significantly longer median persistence times than the employees without a UI/OAB diagnosis.
UA medication adherence as measured by PDC was not high in this study population (Figure 3). Over $45 \%$ of employees had less than $10 \%$ adherence, and less than $13 \%$ had $\geq 80 \%$ adherence during the 12 months after the index date.

Figure 4 shows the relationship between copay and adherence and the relationship between copay as a percentage of salary and adherence, after adjusting for other variables. Adherence was significantly lower for employees paying higher UA medication copays, and adherence was also significantly lower for employees paying a higher proportion of their salaries toward UA medication copays. In the regression model measuring the impact of copays, both the copay $(P<0.001)$ and copay squared $(P<0.001)$ variables were significant. In the regression model measuring the impact of copay as a percentage of salary, both copay as a percentage of salary $(P<0.001)$ and the square of copay as a percentage of salary $(P=0.007)$ were significant. In both the copay and the copay as a percentage of salary models, adherence was significantly higher among employees with urge UI (21.7\%-22.4\% higher), mixed UI (20.5\%-20.8\%), or other OAB diagnosis (11.2\%-11.7\%) than among employees with no UI/OAB diagnosis (all $P<0.05$ ).

Other covariates that were significantly associated with greater adherence included being older, being female, having a specific OAB/UI diagnosis versus not having a diagnosis, being white, having lower pre-index medical costs, and having higher pre-index drug costs. Significant differences in adherence were also found between some health plan groups, regions, and industries. A strength of this study is that it controlled for these and other factors in order to understand the relationship between copay and adherence.

Table 2 provides the regression-adjusted cost, absence day, and turnover rate comparisons between the $<80 \%$ adherence cohort and the $\geq 80 \%$ adherence cohort. Mean medical, sick leave, and STD costs were statistically significantly lower, and mean prescription drug costs were statistically significantly higher in the $\geq 80 \%$ adherence cohort. LTD and workers' compensation costs, absence days, and turnover were statistically similar between cohorts.

\section{Discussion}

This is the first study we are aware of to examine the relationship between copay, salary, and adherence with UA medications and the first study to measure the association between UA adherence and employee cost, absence, and turnover. In this retrospective study of employees prescribed UA medications, median persistence was 64 days, and average adherence was approximately 30\% during the year after the index prescription. Regression-adjusted adherence was significantly higher when either copay or copay as a percentage of the employee's salary was low. When controlling for potentially confounding factors, regression-adjusted mean medical, sick leave, and STD costs were significantly lower, and prescription drug costs were 
Persistence and Adherence with Urinary Antispasmodic Medications

Among Employees and the Impact of Adherence on Costs and Absenteeism

TABLE 1 Descriptive Characteristics of the 2,960 Eligible Employees with UA Prescriptions

\begin{tabular}{|c|c|c|c|c|c|}
\hline \multirow[b]{2}{*}{ Variable } & \multicolumn{2}{|c|}{$\begin{array}{c}\text { Adherence }<80 \% \\
\quad(\mathrm{~N}=2,580)\end{array}$} & \multicolumn{2}{|c|}{$\begin{array}{c}\text { Adherence } \geq 80 \% \\
(\mathrm{~N}=380)\end{array}$} & \multirow[b]{2}{*}{$P$ Value } \\
\hline & Mean or $\mathrm{N}$ & SD or $\%$ & Mean or $\mathrm{N}$ & SD or $\%$ & \\
\hline$\overline{\text { Age }}$ & 46.18 & 10.10 & 49.79 & 9.06 & $<0.001$ \\
\hline Female & 1,792 & $69.5 \%$ & 290 & $76.3 \%$ & 0.006 \\
\hline Married & 1,040 & $40.3 \%$ & 178 & $46.8 \%$ & 0.016 \\
\hline Not married & 595 & $23.1 \%$ & 73 & $19.2 \%$ & 0.094 \\
\hline Missing marital status & 945 & $36.6 \%$ & 129 & $33.9 \%$ & 0.310 \\
\hline White & 997 & $38.6 \%$ & 190 & $50.0 \%$ & $<0.001$ \\
\hline Black & 172 & $6.7 \%$ & 14 & $3.7 \%$ & 0.025 \\
\hline Hispanic & 298 & $11.6 \%$ & 24 & $6.3 \%$ & 0.002 \\
\hline Other race & 49 & $1.9 \%$ & 3 & $0.8 \%$ & 0.124 \\
\hline Missing race & 1,064 & $41.2 \%$ & 149 & $39.2 \%$ & 0.453 \\
\hline Annual salary ${ }^{\mathrm{a}}$ & $\$ 55,453$ & $\$ 37,758$ & $\$ 58,305$ & $\$ 36,572$ & 0.169 \\
\hline Tenure (years with employer) & 10.65 & 9.57 & 12.18 & 10.29 & 0.004 \\
\hline Exempt (salaried vs. hourly) & 1,219 & $47.2 \%$ & 184 & $48.4 \%$ & 0.669 \\
\hline Full time & 2,531 & $98.1 \%$ & 367 & $96.6 \%$ & 0.053 \\
\hline Retail industry & 652 & $25.3 \%$ & 81 & $21.3 \%$ & 0.095 \\
\hline Health industry & 372 & $14.4 \%$ & 66 & $17.4 \%$ & 0.131 \\
\hline Manufacturing industry & 427 & $16.6 \%$ & 63 & $16.6 \%$ & 0.989 \\
\hline Transportation industry & 284 & $11.0 \%$ & 39 & $10.3 \%$ & 0.664 \\
\hline Other & 764 & $29.6 \%$ & 118 & $31.1 \%$ & 0.567 \\
\hline Union & 113 & $4.4 \%$ & 26 & $6.8 \%$ & 0.034 \\
\hline Nonunion & 1,684 & $65.3 \%$ & 230 & $60.5 \%$ & 0.071 \\
\hline Missing union status & 783 & $30.3 \%$ & 124 & $32.6 \%$ & 0.368 \\
\hline Health plan group 1 & 602 & $23.3 \%$ & 65 & $17.1 \%$ & 0.007 \\
\hline Health plan group 2 & 286 & $11.1 \%$ & 42 & $11.1 \%$ & 0.985 \\
\hline Health plan group 3 & 1,692 & $65.6 \%$ & 273 & $71.8 \%$ & 0.016 \\
\hline Urge UI & 181 & $7.0 \%$ & 38 & $10.0 \%$ & 0.038 \\
\hline Mixed UI & 99 & $3.8 \%$ & 21 & $5.5 \%$ & 0.119 \\
\hline Nocturnal UI & 6 & $0.2 \%$ & 0 & $0.0 \%$ & 0.347 \\
\hline Other OAB & 1,007 & $39.0 \%$ & 153 & $40.3 \%$ & 0.646 \\
\hline No UI/OAB diagnosis ${ }^{\mathrm{b}}$ & 1,429 & $55.4 \%$ & 200 & $52.6 \%$ & 0.313 \\
\hline ZIP code 1 st digit $=0$ (New England $)$ & 127 & $4.9 \%$ & 19 & $5.0 \%$ & 0.948 \\
\hline ZIP code lst digit = 1 (Mid Atlantic) & 135 & $5.2 \%$ & 15 & $3.9 \%$ & 0.286 \\
\hline ZIP code lst digit $=2$ (Atlantic) & 271 & $10.5 \%$ & 31 & $8.2 \%$ & 0.158 \\
\hline ZIP code lst digit $=3$ (Southeast) & 286 & $11.1 \%$ & 47 & $12.4 \%$ & 0.460 \\
\hline ZIP code lst digit $=4$ (Great Lakes) & 165 & $6.4 \%$ & 34 & $8.9 \%$ & 0.064 \\
\hline ZIP code lst digit $=5$ (North) & 85 & $3.3 \%$ & 9 & $2.4 \%$ & 0.336 \\
\hline ZIP code lst digit $=6$ (Central) & 172 & $6.7 \%$ & 32 & $8.4 \%$ & 0.208 \\
\hline ZIP code lst digit $=7$ (South) & 847 & $32.8 \%$ & 120 & $31.6 \%$ & 0.628 \\
\hline ZIP code lst digit $=8$ (Mountain West) & 164 & $6.4 \%$ & 24 & $6.3 \%$ & 0.976 \\
\hline ZIP code lst digit $=9$ (Pacific) & 328 & $12.7 \%$ & 49 & $12.9 \%$ & 0.921 \\
\hline Pre-index Charlson Comorbidity Index & 0.395 & 0.978 & 0.461 & 1.030 & 0.223 \\
\hline UA prescription copay (average per 30-day supply) & $\$ 20.15$ & $\$ 31.18$ & $\$ 14.68$ & $\$ 12.48$ & $<0.001$ \\
\hline UA copay as a percentage of salarya & $0.41 \%$ & $0.78 \%$ & $0.33 \%$ & $0.36 \%$ & $<0.001$ \\
\hline
\end{tabular}

higher for employees with $\geq 80 \%$ adherence compared with employees with $<80 \%$ adherence.

The population of employees taking UA medications in this study was similar in several ways to populations of patients from other nationwide studies. Gender distributions and percentage of patients with different types of UI/OAB were similar to those reported in Nitz et al. (2005). ${ }^{57}$ Pelletier et al. (2009) also found a similar gender distribution among 
Persistence and Adherence with Urinary Antispasmodic Medications

Among Employees and the Impact of Adherence on Costs and Absenteeism

FIGURE 2 Adjusted UA Medication Persistence by Diagnosis

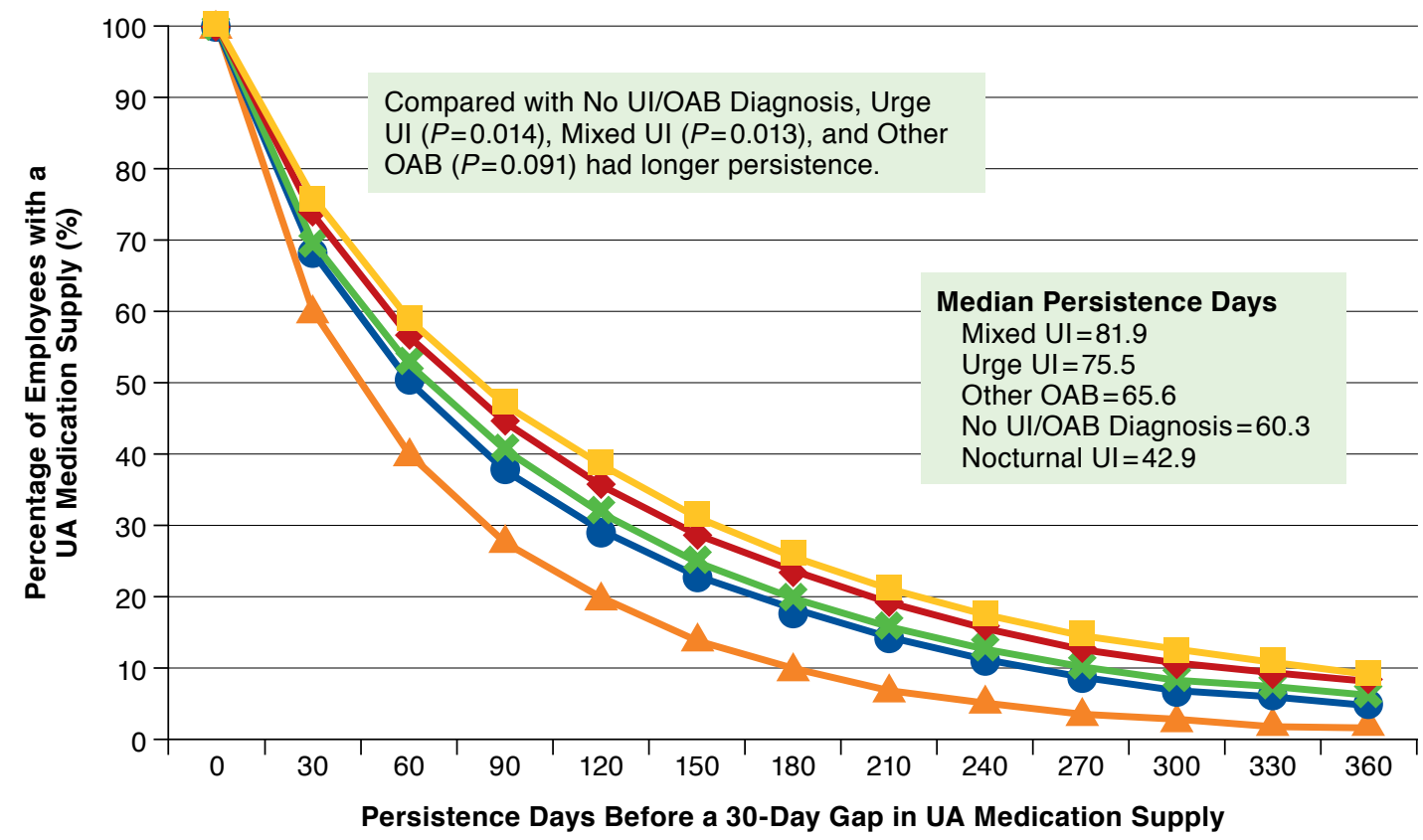

Urge UI $(\mathrm{N}=219)$

Mixed UI $(\mathrm{N}=120) \quad$ Nocturnal UI $(\mathrm{N}=6)$

Other OAB $(\mathrm{N}=1,160)$

No UI/OAB Diagnosis $(\mathrm{N}=1,629)$

$O A B=$ overactive bladder; $U A=$ urinary antispasmodics; $U I=$ urinary incontinence.

pharmacological therapy recipients. ${ }^{37}$ Like the other studies, the current study included a mix of patients from various regions around the United States. The average patient ages in the 2 prior studies were 5-9 years older than in the current study, mainly because those studies were not limited to employees. Thus, the population in the current study is similar to other UA therapy populations in the literature, but focused on employees.

The low persistence with UA medications found in this study (only 5\% continued to take a UA medication for at least a year) is somewhat lower than the anticholinergic class-level persistence (23\% at 1 year) found by Gopal et al. (2008). ${ }^{36}$ However, that study defined the end of persistence as a 90-day gap in supply, rather than the 30-day gap used in this study. Several other studies also reported low persistence (5\%-35\% at 1 year), ${ }^{31,33-35}$ although each examined persistence with a specific UA medication, rather than persistence with any medication in the class.

Similarly, the current study found that only $13 \%$ of individuals were at least $80 \%$ adherent over the year after the index prescription. This is similar to the $14 \%$ found by Pelletier et al. ${ }^{37}$ and lower than the $30 \%$ found by D'Souza et al. (2008). ${ }^{31}$
A study by Yu et al. (2005) found only 5\% of Medicaid patients were $\geq 80 \%$ adherent during a 6 -month follow-up period. ${ }^{32}$ Our study used an $80 \%$ cut point for defining the cohorts for 2 reasons. First, the $80 \%$ cut point allows comparisons to be made with these earlier adherence studies. Second, this high cut point creates an adherent cohort with few skipped doses. UA medications have a short duration of action, so skipped doses quickly lead patients to experience symptoms of UI/OAB.

Although no prior claims studies were found that measured the impact of copay or salary (or income) on adherence, persistence, or the likelihood of discontinuance, medication cost and related factors involving insurance coverage have been identified as reasons for discontinuing UA medications. In a survey of 1,447 U.S. adults who had discontinued UA therapy, the top reasons for discontinuation were poor efficacy (41\%), side effects (22\%), cost of medication (19\%), and lack of insurance coverage for medications (12\%). ${ }^{38}$ Another survey of 1,322 U.S. adults who discontinued found the top 4 reasons to be "didn't work as expected" (46\%), "switched to a new medication" (25\%), "learned to get by without medication" (23\%), and "I had side effects" (21\%). "Cost/amount of copay" (17\%) was the sixth most common reason, and "change of insurance 
Persistence and Adherence with Urinary Antispasmodic Medications

Among Employees and the Impact of Adherence on Costs and Absenteeism

FIGURE 3 Histogram of Annual UA Medication Proportion of Days Covered $(\mathrm{N}=2,960)$

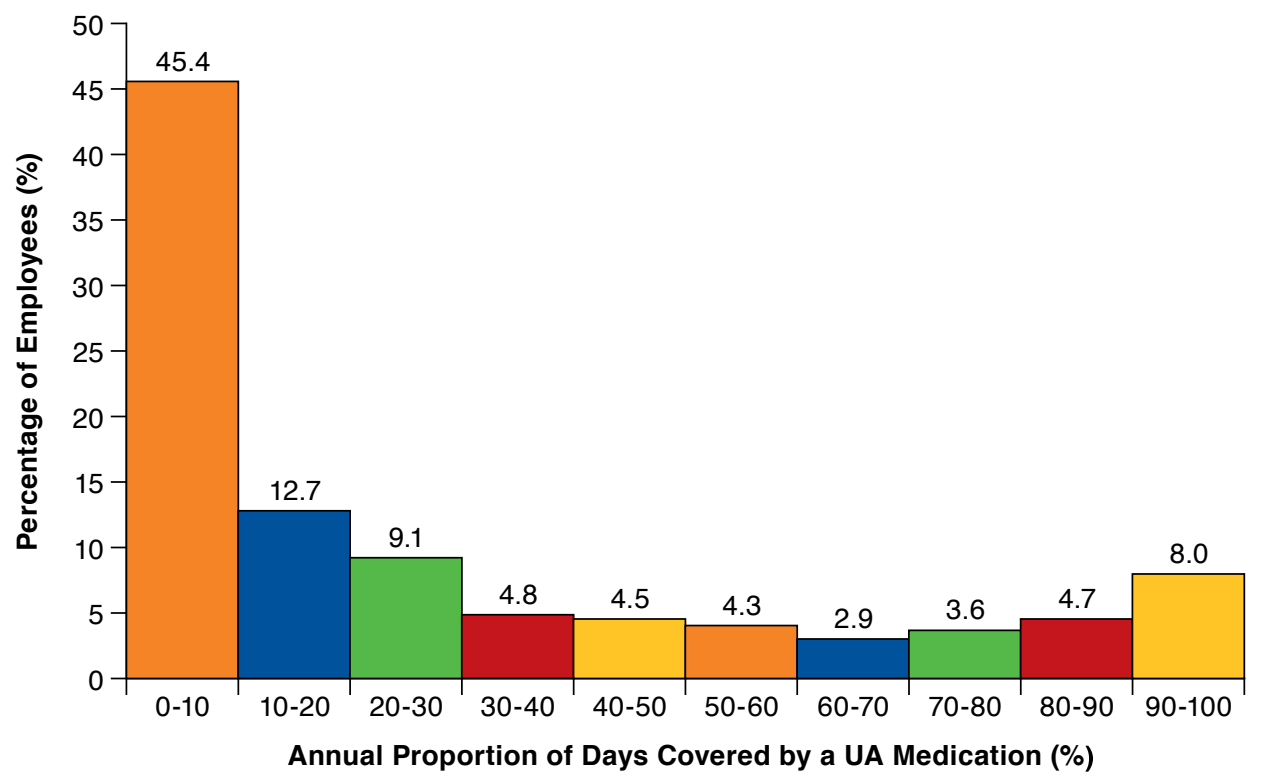

$U A=$ urinary antispasmodics.

FIGURE 4 Proportion of Days Covered Versus Monthly Copay and Copay as a Percentage of Salary $(\mathrm{N}=2,960)$
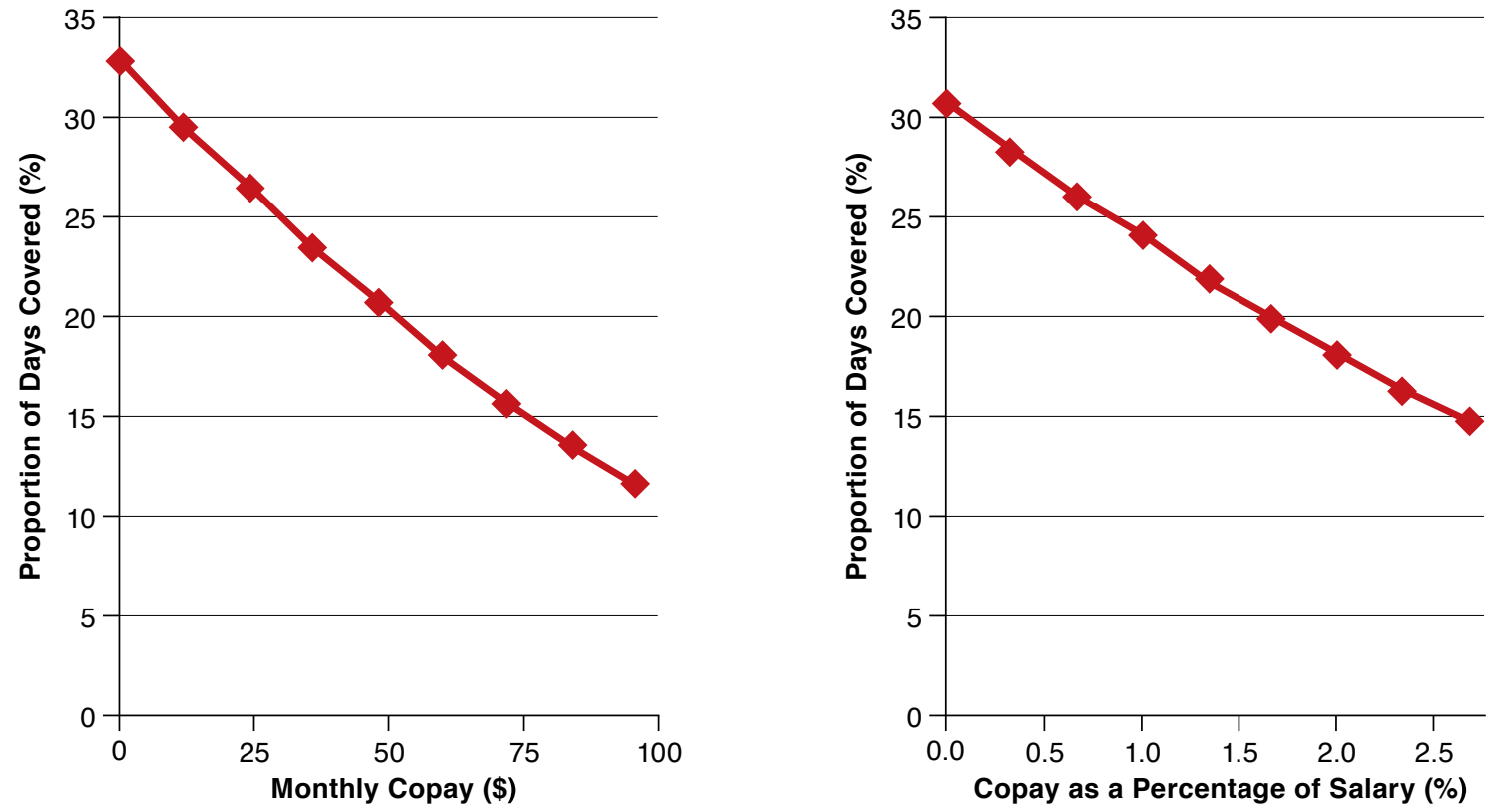

status" (7\%) was the eleventh most common reason. ${ }^{39}$ Our study found that higher copay and the proportion of salary an employee pays toward copays are significantly associated with higher adherence.
Few studies have investigated the relationship between UA adherence and cost or other outcomes. Balkrishnan et al. found that in older adults with $\mathrm{OAB}$, each $10 \%$ increase in antimuscarinic medication possession ratio was associated with a $5.6 \%$ 
Persistence and Adherence with Urinary Antispasmodic Medications

Among Employees and the Impact of Adherence on Costs and Absenteeism

TABLE 2 Comparison of Outcomes for Employees with $\geq 80 \%$ Versus $<80 \%$ Adherence

\begin{tabular}{|c|c|c|c|c|c|c|c|c|c|c|}
\hline \multirow[b]{2}{*}{ Outcomes } & \multicolumn{4}{|c|}{ Adherence $<80 \%$} & \multicolumn{4}{|c|}{ Adherence $\geq 80 \%$} & \multirow[b]{2}{*}{$\begin{array}{c}\text { Mean } \\
\text { Difference }\end{array}$} & \multirow[b]{2}{*}{$\begin{array}{c}P \\
\text { Value }\end{array}$} \\
\hline & $\begin{array}{l}\text { Number of } \\
\text { Employees }\end{array}$ & $\begin{array}{c}\text { Adjusted } \\
\text { Mean, \$, } \\
\text { or Rate (\%) }\end{array}$ & $\begin{array}{l}\text { Adjusted } \\
\text { Standard } \\
\text { Error }\end{array}$ & Median & $\begin{array}{l}\text { Number of } \\
\text { Employees }\end{array}$ & $\begin{array}{c}\text { Adjusted } \\
\text { Mean, \$, } \\
\text { or Rate (\%) }\end{array}$ & $\begin{array}{l}\text { Adjusted } \\
\text { Standard } \\
\text { Error }\end{array}$ & Median & & \\
\hline Medical cost & 2,580 & $\$ 7,799$ & $\$ 181$ & $\$ 3,402$ & 380 & $\$ 5,561$ & $\$ 337$ & $\$ 2,593$ & $\$ 2,238$ & $<0.001$ \\
\hline Prescription drug cost & 2,580 & $\$ 1,897$ & $\$ 32$ & $\$ 1,282$ & 380 & $\$ 3,425$ & $\$ 152$ & $\$ 3,315$ & $-\$ 1,528$ & $<0.001$ \\
\hline Sick leave cost & 813 & $\$ 812$ & $\$ 32$ & $\$ 265$ & 110 & $\$ 640$ & $\$ 74$ & $\$ 31$ & $\$ 172$ & 0.033 \\
\hline Short-term disability cost & 1,711 & $\$ 610$ & $\$ 40$ & $\$ 0$ & 244 & $\$ 387$ & $\$ 78$ & $\$ 0$ & $\$ 223$ & 0.012 \\
\hline Long-term disability cost & 1,890 & $\$ 248$ & $\$ 58$ & $\$ 0$ & 264 & $\$ 1,135$ & $\$ 577$ & $\$ 0$ & $-\$ 887$ & 0.126 \\
\hline Workers' compensation cost & 2,443 & $\$ 174$ & $\$ 19$ & $\$ 0$ & 352 & $\$ 293$ & $\$ 88$ & $\$ 0$ & $-\$ 119$ & 0.187 \\
\hline Sick leave days & 813 & 4.98 & 0.19 & 1.22 & 110 & 4.65 & 0.51 & 0.14 & 0.33 & 0.541 \\
\hline Short-term disability days & 1,711 & 4.33 & 0.28 & 0.00 & 244 & 3.61 & 0.71 & 0.00 & 0.71 & 0.352 \\
\hline Long-term disability days & 1,890 & 3.53 & 0.83 & 0.00 & 264 & 4.46 & 2.68 & 0.00 & -0.94 & 0.738 \\
\hline Workers' compensation days & 2,443 & 0.24 & 0.08 & 0.00 & 352 & 0.33 & 0.22 & 0.00 & -0.09 & 0.693 \\
\hline $\begin{array}{l}\text { Turnover rate } \\
\text { (12-18 months after index) }\end{array}$ & 2,294 & $4.8 \%$ & $0.4 \%$ & $0.0 \%$ & 334 & $5.4 \%$ & $1.2 \%$ & $0.0 \%$ & $-0.60 \%$ & 0.621 \\
\hline
\end{tabular}

decrease in total annual health care costs $(P<0.001) .^{42}$ Ko et al. compared the cost-effectiveness of 8 anticholinergic drugs using data from the literature and found that cost estimates for OAB-induced comorbidities were higher when anticholinergic discontinuation rates were higher. ${ }^{43}$ No other studies of the impact of adherence were found. Thus, the significant differences between nonadherent and adherent cohorts in medical $(\$ 2,238)$, sick leave (\$172), and STD (\$223) costs found in the current study are important additions to the literature (Table 2).

The higher overall drug costs found in the adherent cohort are likely accounted for mainly by the additional UA medications purchased by the employee (copay plus employerpaid portion) when compared with the nonadherent cohort. However, further study is warranted to determine if costs of non-UA medications were higher as well. The lower all-cause medical, sick leave, and STD costs in the adherent cohort compared with the nonadherent cohort are apparently not due to readily measurable differences other than adherence. Factors that often impact medical costs include age, gender, comorbid conditions, and prior costs. These and many other factors were controlled for in this study, and still employees who were more adherent had lower medical costs. These factors along with job-related variables were also controlled for in the sick leave and STD models.

\section{Limitations}

This study has several limitations. First, the study design was retrospective in nature, not randomized, and there may be factors associated with persistence, adherence, cost, or other outcomes that were not measurable or controlled for. Future randomized controlled trials comparing adherent and nonadherent employees before and after starting UA medication therapy would be desirable in order to measure causal effects of adherence on these outcomes. Second, prescription drug insurance claims data were used to identify UA users and to measure medication adherence in the study population rather than more direct measures of use. Mail order prescriptions were included in this study, but the study did not assess the impact of mail order mandates in benefit designs. There may be several less common medications used to treat OAB that were not included in the list of UA medications in this study. Also, although surrogates for overall health were controlled for in the regression models (e.g., prior costs, absences, and comorbidity index values), it was not possible to measure or control for the effects of the severity of the employee's urinary condition.

Third, salary information was only available for the employee. Total family income and salary of family members were not available and may impact the patient's ability to purchase UA medications. Also, the study treats the UA medications as a class rather than comparing the persistence, adherence, or outcomes associated with specific UA medications (oxybutynin vs. tolterodine, for example). This study did not examine whether adherence was more impactful among women versus among men. This is a topic for future study. Another topic of future study would be to examine adherence cut points other than $80 \%$ when defining cohorts, perhaps employees with 1 prescription fill versus more than 1 . Finally, future studies with a greater number of employees in the cost, absence, and turnover comparisons would be beneficial in corroborating these results.

\section{Conclusions}

This study found varying levels of persistence and adherence for different $\mathrm{OAB}$ symptoms, but as in other studies, overall persistence and adherence were low. Economic factors such as ability to pay influence adherence to UA medications, and 
employees with lower copays and employees paying a lower percentage of their salaries toward UA medications were more adherent. Higher adherence was also associated with lower regression-adjusted mean medical, sick leave, and STD costs. Thus, the study gives evidence of potential economic benefits to employers from increased UA adherence.

\section{Authors}

NATHAN L. KLEINMAN, PhD, is Senior Director of Research Services, and AMY ATKINSON, MS, is Senior Data Analyst and Data Analyst Team Leader, HCMS Group LLC, Cheyenne, Wyoming. KEVIN ODELL, PharmD, is Director, Medical Affairs, and KELLY H. ZOU, PhD, PStat, is Director of Statistics, Pfizer Inc., New York, New York. CHIEH-I CHEN, MPH, was Associate Director of Outcomes Research, Pfizer China, Beijing, China, at the time of this study.

AUTHOR CORRESPONDENCE: Nathan L. Kleinman, PhD, 415 W. 17th St., Ste. 250, Cheyenne, WY 82001. Tel.: 307.996.4243; Fax: 307.638.8512; E-mail: nathan_kleinman@hcmsgroup.com.
4. Onukwugha E, Zuckerman IH, McNally D, Coyne KS, Vats V, Mullins CD. The total economic burden of overactive bladder in the United States: a disease-specific approach. Am J Manag Care. 2009;15(4 Suppl):S90-S97. Available at: http://www.ajmc.com/publications/supplement/2009/a220_ 09mar_oab/a220_09mar_onuks90tos97/1. Accessed August 25, 2014.

5. Coyne KS, Sexton CC, Vats V, Thompson C, Kopp ZS, Milsom I. National community prevalence of overactive bladder in the United States stratified by sex and age. Urology. 2011;77(5):1081-87.

6. Sexton CC, Coyne KS, Vats V, Kopp ZS, Irwin DE, Wagner TH. Impact of overactive bladder on work productivity in the United States: results from EpiLUTS. Am J Manag Care. 2009;15(4 Suppl):S98-S107. Available at: http://www.ajmc.com/publications/supplement/2009/A220_09mar_OAB/ A220_09marSextonS98tol07/. Accessed August 25, 2014.

7. Coyne KS, Sexton CC, Thompson CL, et al. Impact of overactive bladder on work productivity. Urology. 2012;80(1):97-103.

8. Kannan H, Radican L, Turpin RS, Bolge SC. Burden of illness associated with lower urinary tract symptoms including oberactive bladder/urinary incontinence. Urology. 2009;74(1):34-38.

9. Irwin DE, Milsom I, Reilly K, et al. Overactive bladder is associated with erectile dysfunction and reduced sexual quality of life in men. J Sex Med. 2008;5(12):2904-10.

10. Sand PK, Appell R. Disruptive effects of overactive bladder and urge urinary incontinence in younger women. Am J Med. 2006;119(3 Suppl 1):S16-S23.

11. Wu EQ, Birnbaum H, Marynchenko M, Mareva M, Williamson T, Mallett D. Employees with overactive bladder: work loss burden. J Occup Environ Med. 2005;47(5):439-46.

12. Tubaro A. Defining overactive bladder: epidemiology and burden of disease. Urology. 2004;64(6 Suppl 1):S2-S6.

13. Milsom I, Abrams P, Cardozo L, Roberts RG, Thuroff J, Wein AJ. How widespread are the symptoms of an overactive bladder and how are they managed? A population-based prevalence study. BJU Int. 2001;87(9):760-66. 14. Toviaz (fesoterodine fumarate) prescribing information. Pfizer Inc. Revised January 2014. Available at: http://labeling.pfizer.com/ShowLabeling. aspx?id=540. Accessed September 9, 2014.

15. Detrol (tolterodine tartrate) prescribing information. Pfizer Inc. Revised August 2012. Available at: http://www.accessdata.fda.gov/drugsatfda_docs/ label/2012/020771s028lbl.pdf. Accessed September 9, 2014.

16. Detrol LA (tolterodine tartrate extended release capsules) prescribing information. Pfizer Inc. Revised August 2012. Available at: http://labeling. pfizer.com/showlabeling. aspx?id=719. Accessed September 9, 2014.

17. Ditropan (oxybutynin hydrochloride) prescribing information. SanofiAventis. March 2012. Available at: http://www.accessdata.fda.gov/drugsatfda_docs/label/2008/017577s034,018211s017,020897s0181bl.pdf. Accessed September 9, 2014.

18. Ditropan XL( oxybutynin chloride tablet, extended release) prescribing information. Alza Corporation. Revised November 2012. Available at: http:// www.accessdata.fda.gov/drugsatfda_docs/label/2012/020897s031lbl.pdf. Accessed September 9, 2014

19. Gelnique (oxybutynin gel) prescribing information. Watson Pharmaceuticals Inc. Revised October 2012. Available at: http://www.accessdata.fda.gov/ drugsatfda_docs/label/2012/022204s006lbl.pdf. Accessed September 9, 2014. 20. Oxytrol (oxybutynin patch) prescribing information. Watson Pharmaceuticals, Inc. Revised October 2012. Available at: http://www.accessdata.fda.gov/drugsatfda_docs/label/2012/021351s008s009lbl.pdf. Accessed September 9, 2014.

21. Vesicare (solifenacin succinate) prescribing information. Astellas Pharma Technologies Inc. Revised October 2013. Available at: http://www.astellas. us/docs/vesicare.pdf. Accessed September 9, 2014.

22. Enablex (darifenacin extended-release tablets) prescribing information. Novartis. Revised October 2013. Available at: http://pi.actavis.com/data_ stream. asp?product_group $=1879 \& \mathrm{p}=$ pi\&language $=$ E. Accessed September 9, 2014. 


\section{Persistence and Adherence with Urinary Antispasmodic Medications Among Employees and the Impact of Adherence on Costs and Absenteeism}

23. Sanctura (trospium chloride) prescribing information. Allergen, Inc. Revised July 2012. Available at: http://www.allergan.com/assets/pdf/sanctura_pi.pdf. Accessed September 9, 2014.

24. Sanctura XR (trospium chloride extended release capsules) prescribing information. Allergen, Inc. Revised August 2012. Available at: http://www. allergan.com/assets/pdf/sanctura_xr_pi.pdf. Accessed September 9, 2014.

25. Flavoxate (hydrochloride tablet, film coated) prescribing information. Paddock Labs. February 2008. Available at: http://edkb.fda.gov/webstart/ arraytrack/PDFfile/LTKB_BD/flavoxate.pdf. Accessed September 9, 2014.

26. Athanasopoulos A. The pharmacotherapy of overactive bladder. Expert Opin Pharmacother. 2011;12(7):1003-05

27. Kreder K, Dmochowski R. The Overactive Bladder: Evaluation and Management. London: Informa UK Ltd.; 2007. Available at: http://books. google.com/books?id=rbjibqsVYCQC. Accessed August 25, 2014.

28. Chapple CR, Khullar V, Gabriel Z, Muston D, Bitoun CE, Weinstein D. The effects of antimuscarinic treatments in overactive bladder: an update of a systematic review and meta-analysis. Eur Urol. 2008;54(3):543-62.

29. Haab F, Castro-Diaz D. Persistence with antimuscarinic therapy in patients with overactive bladder. Int J Clin Pract. 2005;59(8);931-37.

30. Sexton CC, Notte SM, Maroulis C, et al. Persistence and adherence in the treatment of overactive bladder syndrome with anticholinergic therapy: a systematic review of the literature. Int J Clin Pract. 2011;65(5):567-85.

31. D'Souza AO, Smith MJ, Miller LA, Doyle J, Ariely R. Peristence, adherence, and switch rates among extended-release and immediate-release overactive bladder medications in a regional managed care plan. J Manag Care Pharm. 2008;14(3):291-301. Available at: http://www.amcp.org/data/jmcp/ JMCPMaga_April08_291-301.pdf.

32. Yu YF, Nichol MB, Yu AP, Ahn J. Persistence and adherence of medications for chronic overactive bladder/urinary incontinence in the California Medicaid program. Value Health. 2005;8(4):495-505.

33. Shaya FT, Blume S, Gu A, Zyczynski T, Jumadilova Z. Persistence with overactive bladder pharmacotherapy in a Medicaid population. Am J Manag Care. 2005;11(4 Suppl):S121-S29. Available at: http://www.ajmc.com/publications/supplement/2005/2005-07-voll1-n4Suppl/Jul05-2092pS121-S129/. Accessed August 25, 2014

34. Wagg A, Compion G, Fahey A, Siddiqui E. Persistence with prescribed antimuscarinic therapy for overactive bladder: a UK experience. BJU Int 2012;110(11):1767-74.

35. Brostrøm S, Hallas J. Persistence of antimuscarinic drug use. Eur J Clin Parmacol. 2009;65(3):309-14.

36. Gopal M, Haynes K, Bellamy SL, Arya LA. Discontinuation rates of anticholinergic medications used for the treatment of lower urinary tract symptoms. Obstet Gynecol. 2008;112(6):1311-18.

37. Pelletier EM, Vats V, Clemens JQ. Pharmacotherapy adherence and costs versus nonpharmacologic management in overactive bladder. Am J Manag Care. 2009;15(4 Suppl):S108-S14. Available at: http://www.ajmc.com/ publications/supplement/2009/A220_09mar_OAB/A220_09marPelletier_ S108tol14/. Accessed August 25, 2014.

38. Campbell UB, Stang P, Barron R. Survey assessment of continuation of and satisfaction with pharmacological treatment for urinary incontinence. Value Health. 2008;11(4):726-32.

39. Benner JS, Nichol MB, Rovner ES, et al. Patient-reported reasons for discontinuing overactive bladder medication. BJU Int. 2009;105(9):1276-82. Available at: http://onlinelibrary.wiley.com/doi/10.1111/j.1464410X.2009.09036.x/pdf. Accessed August 25, 2014.

40. Sears CLG, Lewis C, Noel K, Albright TS, Fischer JR. Overactive bladder medication adherence when medication is free to patients. J Urol. 2010;183(3):1077-81.
41. Harpe SE, Szeinbach SL, Caswell RJ, Corey R, McAuley JW. The relative importance of health related quality of life and prescription insurance coverage in the decision to pharmacologically manage symptoms of overactive bladder. J Urol. 2007;178(6):2532-36.

42. Balkrishnan R, Bhosle MJ, Camacho FT, Anderson RT. Predictors of medication adherence and associated health care costs in an older population with overactive bladder syndrome: a longitudinal cohort study. J Urol. 2006;175(3 Pt 1):1067-72.

43. Ko Y, Malone DC, Armstrong EP. Pharmacoeconomic evaluation of antimuscarinic agents for the treatment of overactive bladder. Pharmacotherapy. 2006;26(12):1694-702.

44. Butler RJ, Davis TK, Johnson WG, Gardner HH. Effects of nonadherence with prescription drugs among older adults. Am J Manag Care. 2011;17(2):153-60. Available at: http://www.ajmc.com/publications/ issue/2011/2011-2-vol17-n2/AJMC_1lfeb_Butler_153tol60/. Accessed August 25, 2014.

45. Lynch W, Markosyan K, Melkonian A, Pesa J, Kleinman N. Effect of antihypertensive medication adherence among employees with hypertension. Am J Manag Care. 2009;15(12):871-80. Available at: http://www. ajmc.com/publications/issue/2009/2009-12-vol15-n12/AJMC_09Dec_ Lynch_871to880/. Accessed August 25, 2014.

46. Roebuck MC, Liberman JN, Gemmill-Toyama M, Brennan TA Medication adherence leads to lower health care use and costs despite increased drug spending. Health Aff (Millwood). 2011;30(1):91-99.

47. Heisler M, Langa KM, Eby EL, Fendrick AM, Kabeto MU, Piette JD. The health effects of restricting prescription medication use because of cost. Med Care. 2004;42(7):626-34.

48. Balkrishnan R, Christensen DB, Bowton DL. Self-reported health status, prophylactic medication use, and healthcare costs in older adults with asthma. J Am Geriatr Soc. 2002;50(5):924-29.

49. Groban MD, Evans RM, Edgren B, et al. Clinical benefits and cost reduction associated with a comprehensive asthma management programme at a managed care organisation. Dis Manag Health Outcomes. 1998;4(2):93-100.

50. Thompson D, Hylan TR, McMullen W, Romeis ME, Buesching D, Oster G. Predictors of a medical-offset effect among patients receiving antidepressant therapy. Am J Psychiatry. 1998;155(6):824-27. Available at: http://ajp.psychiatryonline.org/article. aspx?articleid=172870. Accessed August 25, 2014.

51. Rizzo JA, Simons WR. Variations in compliance among hypertensive patients by drug class: implications for health care costs. Clin Ther. 1997;19(6):1446-57.

52. Kleinman NL, Rohrbacker NJ, Bushmakin AG, Whiteley J, Lynch WD, Shah S. Direct and indirect costs of women diagnosed with menopause symptoms. J Occup Environ Med. 2013;55(4):465-70.

53. Kleinman NL, Cifaldi MA, Smeeding JE, Shaw JW, Brook RA. Annual incremental health benefit costs and absenteeism among employees with and without rheumatoid arthritis. J Occup Environ Med. 2013;55(3):240-44.

54. Kleinman NL, Sadosky A, Seid J, Martin RC, Labiner DM. Costs, work absence, and adherence in patients with partial onset seizures prescribed gabapentin or pregabalin. Epilepsy Res. 2012;102(1):13-22.

55. Charlson ME, Pompei P, Ales KL, MacKenzie CR. A new method of classifying prognostic comorbidity in longitudinal studies: development and validation. J Chronic Dis. 1987;40(5):373-83.

56. U.S. Department of Labor. CPI detailed report: data for June 2011. US city average Consumer Price Indices for medical services, prescription drugs, and all consumer goods. Available at: http://www.bls.gov/cpi/ cpid1106.pdf. Accessed August 25, 2014.

57. Nitz NM, Jumadilova Z, Darkow T, Frytak JR, Bavendam T. Medical costs after intiation of drug treatment for overactive bladder: effects of selection bias on cost estimates. Am J Manag Care. 2005;11(4 Suppl):S130-S39. Available at: http://www.ajmc.com/publications/supplement/2005/200507-voll1-n4Suppl/Jul05-2089pS130-S139/. Accessed August 25, 2014. 